\title{
Education standards of APA: example of Palacky University in Olomouc
}

\author{
Hana Valkova
}

Fakulty of Physical Culture, Palacky Universitý in Olomouc

Abstract

Adapted Physical Activity (APA) is defined as a multidisciplinary domain included under the roof of inanthropology. The basic principles of APA understanding like 1) the contact theory, 2). phenomenon of "the differen", 3). a categorical environmental approach, 4). the motor competence, 5) movement and activity modifications, 6). an independent living) are described. Main concepts of APA (education, a field practice, and research) are presented. A background of the APA study program at Palacký University in Olomouc is described in relation to the Bologna declaration and AEHESIS (the European study concept of employability). Four study modules (pedagogy, special education, physical education, and adapted physical activity are explained as well as proportions between the theory and practice. International APA study networks and research approaches are shown as good chances for students' mobility.

Keywords:

Bologna declaration, AEHESIS, study module, motor competence, inclusive $\mathrm{PE}$, attitudes toward disability 


\section{Adapted Physical Activity: the development of the definition, recent terminology}

The term Adapted Physical Education (APE) started in the USA in the 50s (last century). The term was recommended by AAHPER (later re-named: AAHPERD American Association for Health, Physical Education and Recreation and Dance) in spite of the term "corrective physical education" was used. Adapted Physical Education is considered as the term focused typically on education. APE represents a completely innovated study and a professional branch of Human Movement Sciences, or Sports Sciences, Kinanthropology, Physical Education (PE) [1].

The Adapted Physical Activity is a broader term, which underlines the process of the adaptation, the activity, equipment, and environment related to every individual with special needs. APA is perceived as the "umbrella term for services that promote active, healthy lifestyle by remediating psychomotor problems" [2].

Despite the fact that the term Adapted Physical Education (and the follow-up terminology) came to Europe from the USA, the roots of APA originated in Europe. The Central Europe played an important role. The historical background since the times of Johan Amos Comenius period, through renaissance and humanism represented by great names of the Enlightenment such as Itard, Seguin, Ling, Montessori, Peterson, etc., are described in several education issues $[3,4,5,1]$. The term moved to Scandinavian countries (mainly Norway in the 70s) and from this part of Europe to the Central Europe (in the 90s). The terminology was step by step changed related to the acceptance or rejection of "different persons", recruited from the following terminology: minorities, marginal groups, extraordinary people, challenged people, persons with special needs, persons with disability - handicap - impairment. Terminology problems are polluted with cultural, educational, traditional differences as well as problems with translation from English language into home languages, especially into Slavic languages in either the education domain (defectology, special education) or the kinanthropology /kinesiology domains (corrective physical education $/ \mathrm{PE} /$, therapeutic $\mathrm{PE}$, a special physical activity, a psychomotor therapy, sports for disabled, adapted physical education or activity).

The principle of the terminology use and understanding here is the social acceptance, and psychological attitudes to "different people" in various settings. The recent worldwide accepted terminology is: Special Education and Adapted Physical Activity or Physical Education [5].

The Adapted Physical Activity is considered as the broader concept which includes the range of services in domains related to:
- performance interest (recreation level, school PE, top competitive sports),

- content of activity (water - indoor - outdoor activity),

- age of population (from early childhood to senior age),

- category or individual diagnoses of "different" (phenomenon "the other"),

- environment, setting (inclusive - parallel - separated),

- focus on matters of management, education, research.

APA understanding is a little different in different countries: from the traditional 4 "categories of the disability" (physical-motor, perceptive-hearing, visual, mental-intellectual) to the recent approach: the respect for all minority groups which need special education, social and psychological attention; people with a social disadvantage (abused, neglected, psychiatric patients, immigrants, victims of war or natural disasters) as well as individuals in the sensitive age of the developmental process such as preschoolers, seniors, or high gifted people such as gifted children of different aspects [6].

In spite of the several different definitions of APA $[7,8,9,2,3]$ all of them underline: multidisciplinarity, a cross-sectional approach; adaptations, modifications of different domains in the life or physical activity settings; the respect to individual limits and abilities; a healthy life style, a quality of life and well-being (www.ifapa.biz - IFAPA, International Federation in APA). Related to Central European cultural and education development as well as previous definitions the APA is formulated as the multidisciplinary structured system of the total context of physical and movement activities (including sports) of individuals with specific needs: either in a separate/ special, parallel or a general/inclusive setting. The domains of structured system are realized in harmony with interests, abilities, or limits of the participating individuals. In the situation, where personal and chronic limits of an individual are fixed, it is necessary to adapt the environment related to the aspects of communication, methods, the content of the activity (the program), rules and regulations, conditions like accessibility, setting, tools/ equipment, assistance $[5,10]$.

The APA is approved as a reputable part of "kinanthropology", and similar branches: kinesiology, human movement sciences, sports sciences $[11,12,13,14]$. Under the umbrella of "kinanthropology" three main parts are developed and cultivated:

- practice: field process development, projects creation, programme management, arrangement of events,

- education of leaders, educators, teachers, coaches, participants of various settings,

- research: analyzing of issues and upcoming topical problems with a follow-up recommendation for practice. 


\section{How to understand APA: the principles}

Out of historical background relevant to the recent APA (see above), real APA was codified in European Charter of Sports for all handicapped people [15]. Three main ideas, among others, are included in this document proved by CDDS:

- the right for an active leisure time, including physical activities and sports,

- the right to be educated with a professional staff,

- the right to be educated for a future profession within $\mathrm{PE} /$ sports domains.

Knowledge of APA definition and mastering its skills are important parts of the APA development, but it is not enough. Attitudes toward basic issues, attitudes to the special environment, to different people are very important as well. The acceptance of the basic principles can provide a better understanding of a broad issue of APA and improve positive attitudes:

1. The contact theory: a personal contact, participation with people in real situations can influence experience more than knowledge, pictures, videos, etc. Personal experience can influence intrinsic beliefs. The arrangement of meetings of all children with attractive program like Inclusive Children Days, the Days of Minorities, Open Doors, Bridges, Paralympics Day, Get into It, Let's be together, etc., are very suitable .

2.Perception of the "phenomenon to be the different": different is not a label for negation, low respect, inferiority, disability. It is just being different. Everybody is different and everybody should respect differences. Perception of the different is seen from the following aspects:

- philosophical: a question - what/who is "normal", what "different" means related to - culture; historical context; macro-, micro- environment;

- psycho-social: the phenomenon can be unknown, displaced, outside or nearby; later in an interest, even accepted and included;

- bio-social: somatic, motor, health variables.

3. Categorical - non-categorical concept: to determine an individual in the category (eg.: a person with a visual impairment) can be useful only for general understanding. Every individual is a special unit. An approach, communication, as well as programs have to be fitted for the individual, not only for the category. The categorical approach is oriented toward disability, treatment and it quite often provokes exclusion. The non-categorical approach stresses the ability, adaptation of conditions, and it provokes an inclusion and an independent living concept.

4. Movement (mobility) as the category of philosophy: a priority of movement understanding is the movement as a part of one's personal being, his/her daily life, so- cial and family life, social care, transport, education, job. Last, but not least, there are leisure activities and sports involved. Subsequences of movement should :

- if it is possible, to provide independent, free movement; if it is not possible then within the individual's limits,

- provide adapted movement acts, skills; if it is not possible then within the individual's limits,

- provide assisted movement (a person, dog, etc.); if it is not possible then within the individual's limits,

- provide movement with compensatory or adapted tools; if it is not possible then within the individual's limits,

- provide passive movement; if it is not possible then within the individual's limits,

- provide movement around; if it is not possible then within the individual's limits,

- provide movement in communication: verbal, visual, mental; if it is not possible then within the individual's limits,

- keep the hand and be with...

5. The principles of adaptation: there is need to adapt environment, facilities, tools because the individual is limited from various aspects (compare APA definition). The following issues can be considered as fundamental:

- communication (style),

- teaching methods, motor learning methods,

- content of activities, programs,

- rules of activity, sports,

- conditions, environment: accessibility, facility/ room, adapted tools, personal support.

Within the top competitive sports environment the special system of sports classification is applied.

6. The principle of independent living: it is necessary to obtain attitudes, skills, and knowledge so that other person can be independent within real limits as much as possible. When you would like to provide the meal to somebody for one day, give him/her fish (a charity approach). When you would like to provide a meal to somebody for the rest of his/her life, teach him/her to catch fish (an independent living approach). Help when it is necessary. This principle is defined as the "theory of empowerment" in the original literature $[16,3]$.

\section{APA and education, study programs}

The high-volume concept of APA needs specialists, professionals in APA. The multi-disciplinary APA system leading to the quality of life has to be underpinned with knowledge and information usually based on research results proved in practice $[7,3]$. Since the 90 s there has been a dramatic development of universities of physical education, and physical activity study 
program in Europe. Apart from traditional PE teaching and coaching new studies, like sports management, leisure time study, health and fitness promotion appeared. Changes were evoked by job market needs, technology development, external pressure of life-style commerce, internal interests and beliefs in fitness and health prevention.

Network of Aligning a European Higher Education Structure in Sport Science (AEHESIS) analyzed the European more frequented PE studies and professions in Europe. An assessment was carried out by Sports University in Cologne (www.enssee.de).

Four main trends were found:

1. PE teaching: PE teaching +2 nd subject; $P E$ and sports (leisure, different levels of age),

2. sports management,

3. health and fitness,

4. coaching.

Due to a multidisciplinary system of APA the graduates can be accepted in all four professional categories: $\mathrm{PE}$ teachers in inclusive education in regular schools, in special schools as well as in out-school environment, management, communal policy, coaching in recreation or competitive top sports. This is probably the first reason why the APA profession was not recognized as the separate professional branch in Europe by AEHESIS investigation even though Renson included the APA in a profession and study network in Europe in 1990 [14]. The second reason can be the lack of attention towards physical activity and sports, lack of attention towards the quality of life of persons with a disability. The countries solving problems with different types of minorities and integration/inclusion has to stress APA in life-span context and education. A European THENAPA project (Thematic network for Adapted Physical Activity) recommended to include minimum 6 credits of basic APA education cluster for all future physical education teachers, sport managers, physiotherapists and other professional dimension in "kinanthropology" and similar others [17]. An APA study in Europe is based on different bases, called like:

A. sandwich study:

- physiotherapy plus additional study of psycho-pedagogy (e.g.: Belgium, Poland);

- additional specialized course, (e.g.: France, Italy);

B. module study:

- national standards (e.g.: USA, Virginia: [12]);

- PE teaching plus special education (Olomouc University example: $[1,10])$.

The module system is one of the Bologna declaration principles. "In order to maintain the new philosophy of student-centered and competence-based learning the Bachelor and Master programs should be organized in modules. These modules are "self-contained, formally structured learning experiences. They should have a coherent and explicit set of learning outcomes, expressed in terms of competences to be obtained, and appropriate assessment criteria" (Quot.: www.eseip.eu/index. php?option).

Module system signifies composition of courses, subjects, disciplines (including content, intensity, requirements) which: a) provide professional competences; b) are closed within a complex examination (in the Czech Republic the state examination); c) can be a part of different study branches, including international studies (open system); d) can provide life education [1]. The APA study at the Faculty of Physical Culture (Palacky University in Olomouc) was opened in 1991 and has been developed under internationally recognized study. This is the reason for the structure and system as described below. Bologna declaration is the basic principle of this study concept:

- three standard levels of Higher Education in Europe are respected: Bc university study equals level IV, MA study equals level V, European MA equals level V+, Ph.D equals level VI, European PhD equals level VI+; - structured study: Bc - MA - Ph.D: provides study and professional competencies, study comparison within Czech Republic, within European universities, chance to get a job in a European context;

- European Credit Transfer System (ECTS): a study load for students about 25 hours $=1 \mathrm{Crp} ; \quad$ Bc usually 180 Crp = 3year study; MA usually 120 Crp = 2year study; Ph.D usually 3-4 study years. Some study clusters of subjects/disciplines are obligatory (A), some of them obligatory-facultative (B), some of them free optional (C);

- Module composition: study and professional competency.

The following example of the APA consists of 5module level (either of them on $\mathrm{Bc}$ and on MA) finished with a state examination. Differences between $\mathrm{Bc}$ and MA level are in practical professional orientation: direct fields practice $(\mathrm{Bc})$, school teaching, leading and theoretical orientation (MA).

1. Module interactive - teaching competencies consists of e.g.: pedagogy, psychology, developmental psychology, sport psychology, sport sociology, philosophy, sports history, law and legislation (including disabilities environment).

2. Module PE Teaching Program - competency for job in kinanthropology, PE teaching and PE sports coaching in general setting, consists of e.g.: biology and medicine disciplines (anatomy, exercise physiology, etc.), physical activity and sports (athletics, swimming, children games, sports games, summer and winter outdoor activities, etc.). 
3. Module Special Education - competency for a job in special or inclusive setting, in the environment of special population, advisory centers, special schools, governmental or local networks oriented on minorities, consists of e.g.: special education, ophtalmopedy, surdopedy, somatopedy, psychopedy, etc.

4. Module APA Didactics - competency for a job in special or integrative environment in schools, governmental and/or communal policy, either in recreation or top-competitive setting, consists of e.g.: (PE - basketball) - wheelchair basketball; (PE - swimming) swimming of $\mathrm{CP}, \mathrm{MD}$, amputees, Halliwick method; (PE - skiing) - mono-skiing, blind skiing; training in inclusive programs; practice in schools, in centers, special institutions, camps, etc.

5. Module Final Bc. or MA theses - competency to prepare, develop, present program for practice $(\mathrm{Bc}$ theses) and for research arguments available for practice (MA theses). This module is linked with research system of institution.

A comprehensive approach towards curricula, education and interactive work with students (besides 6 principles for APA understanding) can be grouped in education, formation, cultivation, improvement of:

- Attitudes: phenomenon of „the other“, difference, tolerance, multiculturalism, life socialization, integration as a life-span context. Inclusive education applied in reality as APA study program is open to students with disability. Recently 16 students with disabilities were included into APA study and 8 graduates received jobs in practice. An effort towards inclusion of students with special needs - usually skilled sportsmen (with adequate support) can serve as positive patterns for understanding of the phenomenon "the others" of all PE inclusive process participants.

- Knowledge: principles of adaptation, categorical non-categorical approach, healthy behavior, health prevention, legislation.

- ,Didactic“ and practical skills: skills of basic mobility as accompanying person; personal skills in physical activities followed with didactic skills; modifications related to program content, age, abilities and limits; experience in communication, in inter-active events; management of special activities, practice in schools, centers; volunteering in different domains like Paralympic Days, Special Olympic Games, outdoor summer-winter camps, weekend events [1]. Students' work can provide inclusion of "different" persons into general social life context. Developmental grant of European fund No: CZ.1.07/1.2.00/08.0117 "Centers for support of integration" is very good platform for undergraduates, volunteers and teachers practice as so as transfer of information (www.apa.upol.cz).
RED LINE of APA approach is the slogan "EVERY INDIVIDUAL IS A CHALLENGE” [3, 8].

\section{Full time study, part time study}

There is need to emphasize the relation between a fulltime (present, day-to-day) study and a part-time study (Czech terminology - combined study). A combined study means a combination of weekend direct teaching and tutoring (approx. 6 weekends each study year plus out-door camps) with e-learning support and self-preparation. This form of study is fully relevant to day-to-day study: the same study modules, subjects-courses, requirements and exams, the amount of credits, the length of study, equal rights, opportunities and responsibilities and duties. The form was typical for students who either a) wanted to receive the level of education, re-qualification, or b) are included in a job without certification and need to receive the requested level of education.

Due to socio-economy changes we feel different trends in students' behavior: to pass Bachelor level in present study, they search strongly for a job and jump to combine form in the Master level study. The feedback of graduates is important for a faculty response: to emphasize practical sports and didactic skills including program composition for persons in environment of ,different" children-students into Bachelor level, to underpin teaching approaches, APA didactic skills into MA level. Students of combined form are recruited either from APA or teaching environment - in this situation it is possible to modify teaching interrelationship as opposed to adaptation which can be realized in the situation of students from other jobs, mostly in management practice.

The combined study programs seem to be a European trend. Institutions should react in scheduling theory and training of skills, e-learning system, week-end studies, etc. The environment of P.E. in general (including APA) is still a little bit conservative. Students of a combined study form can use their practical knowledge for MA theses which seems to be slight advantage. A chance for international study is possible with a disadvantage to leave a job.

\section{International cooperation and research}

International cooperation under the umbrella of APA study programme was initiated with the European Charter of Sports for all: handicapped people [15] respectively both in education study programs and developmental networks. Historically the first European study program was EMDAPA (European Master in APA, level V+) lasted from 1991 up to 2005 - coordinator University in Leuven. A parallel program, Central European Exchange Project of University Study (CEEPUS) in APA was es- 
tablished in 1995, aiming to level study structure and study chances for students from "countries expecting to be involved in European Union". APA concept started in 1997, coordinator of universities - University in Olomouc (www.ceepus.cz).

EMDAPA program was innovated with ERASMUS MUNDUS APA program (2005). Program was oriented on collaboration of EU and non-EU students. Consortium of universities was composed of: University in Leuven - Belgium as coordinator and participants:

- University in Limerick - Ireland,

- University in Olomouc - Czech Republic,

- University in Oslo - Norway.

Representatives of the third countries are: Queensland University (Brisbane - Australia), Charlotteswille University (Virginia - USA) and Stellenbosch University (Stellenbosch - South Africa Republic). Recent Erasmus-Mundus APA II continuous in 2-year study program with the same consortium. University in Warsaw is an additional partner. Former DEUAPA - intensive programme in APA lasted 6 weeks, French being the first language. Program started in Milano (leader prof. Anna Bianco), moved to Torino, camp Pallanza, after that to Bordeaux, Paris. Since 2010 study programme is organized by Helsinki University in Finland (www.haaga-hellia.fi/eudapa) as Erasmus APA study in English. Olomouc University is included as the partner in each of the described programs [1].

The most important aims of APA research are: a) to improve the situation in practice; b) to improve intellectual know-how and theory. Research in this area should be oriented on the topics relevant to practice in PE/sports in separate, parallel or inclusive setting [18].

Declared characteristic features of APA research are: - multi-, inter-, cross-disciplinary approach,

- linking theory and practice,

- trends from descriptive to creative research,

- priorities defined by relevant international - national

associations, like: IFAPA, EUFAPA, IPC, INAS-FID,

SOI and others.

European research program Marie Curie (MC IEF) is available for young investigators and doctoral students, as well as for experienced experts in research. Projects are open for interested investigators from all European countries under selected successful research projects. It is a privilege for the significantly known centers of APA to cooperate under umbrella of international projects.

European Federation of Adapted Physical Activity (EUFAPA) followed the basic ideas of former EARAPA. Related to the recent constitution, clarified in Olomouc 2006, EUFAPA is located in Olomouc, Palacký University, Faculty of Physical Culture. EUFAPA is a European organization focusing on promotion and dissemination of experiences, results and findings in the fields of adapted physical activity and sports science and their practical application to the benefit of individuals across the life span (www.eufapa.upol.cz). Besides research presented in online journal (EUJAPA) EUFAPA is focused on education in APA of pre-service, in-service teachers, educators as well as on practice. The main idea is attention to integration/inclusion in recreation and school setting. Due to a very good website information system, networking of European APA, students and teachers can be informed about new chances for study mobility, volunteering and research possibilities within European cooperation.

\section{Conclusion}

Education standards in APA are based on:

a) APA definition as the wide multi-disciplinary and cross-disciplinary structured system of all physical, movement and sports activities of persons with special needs in either separated, or parallel or inclusive environment which are realized with respect of interests, abilities and limits of participants;

b) APA professionals are needed in field practice, education and research;

c) Six principles of APA understanding: 1. contact theory; 2. perception of "phenomenon the different"; 3. categorical - non-categorical concept; 4. movement (mobility) as the category of philosophy; 5 . principles of adaptations; 6. principle of independent living.

APA study program (BC and MA) is structured in modules related to professional competences:

- interactive, teaching competence;

- PE teachers program;

- special education; - APA didactics;

- final theses.

The equal program for full-time, a part-time study organization.

Development of attitudes, knowledge, „didactic“ and practical skills form a cohesive approach to curricula. International networks (EUFAPA) linked with research can be of a great chance for students as well as professionals and volunteers.

\section{References}

1. Válková H. Students - teachers of European mobility under umbrella of Adapted Physical Activity study program. Studies in Physical Culture \& Tourism 2009; XVI(4): 413-420.

2. Sherrill C. Adapted Physical Activity, Recreation and Sport. Cross disciplinary and Lifespan.5th edition. The McGraw-Hill Companies, Inc; 1998.

3. Doll-Tepper, G. et al. New horizons in sport for athletes with disability. In Proceedings of APA Conference. Berlin: Meyer \& Meyer; 1989. 
4. Kudláček M. European special education and APA history. Studia Kinanthropologica. CEEPUS 59 workshop; 2005.p. 57-61. České Budějovice: Jihočeská Univerzita.

5. Válková H. Adapted Physical Activity - university study in Central Europe: development and recent situation. In: MilanovičD, Prot F, editors. 4th International conference on Kinesiology: Science and profession, challenge for the future; 2004. Opatija, Sept. 7.-11. Zagreb: University of Zagreb; 2005. p. 772-774.

6. Válková H. Teoretickévymezení APA jakokinantropologickédisciplíny: co to je, když se řekne APA (aplikovanépohybovéaktivity). Aplikovanépohybovéaktivity v teoriia praxi; 2010. Vol. 1, p. 25-33.Olomouc: UniverzitaPalackého.

7. DePaw K, Gavron S. Disability and sport. Champaign IL: Human Kinetics; 1995.

8. Doll-Tepper G, DePaw KP. Theory and practice of adapted physical activity: Research perspectives. Sport Science Review. Adapted Physical Activity Quarterly 1996; 5(1): 1-11.

9. Rodrigues D. Adapted Physical Activity or Adapted Motor Activity. Proceedings European Master in APA; 1995. p. 72-74. Leuven: Catholic University in Leuven; 1995.

10. Valkova H, Morisbak I. What is adapted Physical Activity? In: Van Lent M, editor. Count me in: A guide to Inclusive Physical Activity, Sport and Leisure for Children with a Disability; Leuven: Acco; 2006. p. 19-21.

11. Haag H. Theoretical Foundation of Sport Science as a Scientific Discipline. Contribution to a Philosophy (Meta-Theory) of Sport Science. Schorndorf: Hofmann; 1994.

12. Kelly L. Adapted physical education national standards. $2^{\text {nd }}$ edition. Champaign, IL:Human Kinetics, Inc; 2006.

13. Kirk D. Physical culture, physical education and relational analysis. Sport, education \& society 1999; 4(1), p. 63-73.
14. Renson, R. From physical education to kinanthropology: a quest for academic and professional identity. International Journal of Physical Education 1990; 27(1).

15. European Charter of Sports for all: handicapped people. Brussels: CDDS; 1987. Czech version Válková H, editor. Praha: Ministry of Education, Youth and Sports; 1993.

16. Hutzler Y. Empowerment of individuals of disabilities through physical activity: State of the art. In: Dinold M, Gerber G, Reinelt T, editors. Towards a society for all through adapted physical activity. Proceedings of the $13^{\text {th }}$ ISAPA, Vienna; 2001. p.57-65. Vienna: Austrian Federation of Adapted Physical Activity; 2003.

17. Dinold M, Valkova H. Inclusion in Physical Education in School. In: Van Coppenolle H, De Potter JC, editors. Inclusion and integration through Adapted Physical Activity. Leuven: Acco, University Publisher; 2004.

18. Válková H. Process of integration, inclusive PE and university APA study. In: Milanovič D, Prot F, editors. Proceedings Book of 5th International scientific conference on kinesiology - research trends and application. Zagreb: University Zagreb, Faculty of Kinesiology; 2008.

\section{Important contacts:}

1. www.aehesis.com

2. www.aiesep.com

3. www.apa.upol.cz

4. www.ceepus.cz

5. www.enssee.de

6. www.eseip.eu

7. www.eufapa.upol.cz

8. www.europa.eu.int/comm/education/).

9. www.europa.eu.int/comm/education/programmes/ mundus/index en.html

10. www.eusapa.upol.cz

11. www.haaga-hellia.fi/eudapa

12. www.icsspe.com

13. www.ifapa.biz 